\title{
Prevalence of dry socket following extraction of permanent teeth at Kathmandu University Teaching Hospital (KUTH), Dhulikhel, Kavre, Nepal: A study
}

\section{Upadhyaya $C^{1}$, Humagain $M^{1}$}

${ }^{1}$ Lecturer, Department of Dentistry, Dhulikhel Hospital, Kathmandu University Teaching Hospital (KUTH), Dhulikhel, Nepal

\begin{abstract}
Background: One of the most common postoperative complications following the extraction of permanent teeth is a condition known as dry socket. Although the aetiology of dry socket is debated, it is probably multifactoral, and its pathogenesis remains unknown.

Objectives: The aim of the study was to evaluate incidence of dry socket following extraction of permanent teeth at dental out-patient department (OPD) of Dhulikhel hospital, Kathmandu university teaching hospital (KUTH), Kavre, Nepal.

Materials and methods: Retrospective reviews of records of total 1860 no of patients were studied who underwent extraction of permanent teeth for various reasons since January 2007 to December 2008 period. There were 873(47\%) male patients and 987(53\%) female patients. Information regarding indications for extraction, extracted tooth status, onset of symptoms, relevant findings of the examining clinician, interval between presentation, management given, and its outcome were retrieved and analysed.

Results: A total 1860 no of patients were studied who underwent extraction of total 2640 number of permanent teeth for various reasons. A total of 103 (3.9\%) extractions were complicated by dry socket in patients aged 11 to 80 years with female predominance $(54.4 \%)$.

Conclusion: The etiology of dry socket is multifactorial and ultimately it is the host's healing potential which determines the severity and duration of the condition. The incidence of dry socket was found as $3.9 \%$ in this study. The incidence was higher in female patients $(54.4 \%)$ and in mandibular teeth extraction cases $(68.93 \%)$.
\end{abstract}

Key words: Extraction, Dry socket, Teeth

$\mathrm{O}$ ne of the most common postoperative complications following the extraction of permanent teeth is a condition known as dry socket. This term has been used in the literature since 1896, when it was first described by Crawford ${ }^{1}$. It is characterized by severe pain starting usually on the second or third day postoperatively. Its prevalence has been reported to vary from $0 \%$ to more than $35 \%{ }^{2}$ and is more common following mandibular third molar extraction ${ }^{3}$. Although the aetiology of dry socket is debated, it is probably multifactoral ${ }^{4}$, and its pathogenesis remains Unknown ${ }^{5}$. Some of the factors implicated in its aetiology include hypovascularity due to the density of bone ${ }^{6}$, vasoconstriction activity of the local anaesthetic agents ${ }^{7}$, presence of underlying systemic conditions, imbalance of vitamin levels, contraceptive pills ${ }^{8}$, smoking, age and gender ${ }^{8}$, and trauma ${ }^{9}$.

\section{Materials and methods}

This study was done at a community based Kathmandu university teaching hospital (KUTH), Dhulikhel Hospital, Kavre, Nepal. Retrospective reviews of records of total 1860 no of patients were studied who underwent extraction of permanent teeth for various reasons since January 2007 to December 2008 period. There were $873(47 \%)$ male patients and $987(53 \%)$ female patients. Information regarding indications for extraction, extracted tooth status, onset of symptoms, relevant findings of the examining clinician, interval between presentation, management given, and its outcome were retrieved and analysed.

Correspondence

Dr. Chandan Upadhyaya

Lecturer, Department of Dentistry, Dhulikhel Hospital, Kathmandu

University Teaching Hospital (KUTH), Dhulikhel, Nepal

E-mail: updch@yahoo.com 
Results

During the study total 2640 no. of permanent teeth were extracted of 1640 patients. Out of the 1640 no of total patients $987(53 \%)$ patients were female and $873(47 \%)$ patients were male. A total of $103(3.9 \%)$ extractions were complicated by dry socket in patients aged 11 to 80 years. $56(54.4 \%)$ dry sockets were occurred in female patients and $47(45.6 \%)$ occurred in male patients.

The highest frequency of dry socket was in the 21 to 30 -year age group $(40.77 \%)$ followed by more than 51 year age group $(13.59 \%)$ of patients. The indications for extraction of the total 103 no. of dry socket cases are shown in table 2. Advanced dental caries was the reason for extractions of most $46(44.6 \%)$ of cases of dry socket. This was followed by advanced periodontal disease in 42 (40.7\%), pericoronitis in $11(10.6 \%)$, orthodontic reasons $2(1.9 \%)$ and prosthetic reasons 2 $(1.9 \%)$ no of patients. most of the dry socket cases were occurred in mandibular teeth $71(68.93 \%)$ than maxilla 32 (31.06\%). The mandibular first molar 28 (27.81\%) had highest incidence of dry socket occurrence followed by mandibular second molar $13(12.62 \%)$ and premolars $13(12.61 \%)$ and maxillary first molar11 (10.67\%) followed by mandibular third molar $11(10.67 \%)$.

Pain was the chief complain of all cases with dry socket. A combination clinical features of pain, empty socket, bare bone and halitosis present in $60(58.25 \%)$ no of cases. This was followed by the presence of pain,empty socket, and bare bone without halitosis in 20(19.41\%) no of cases. pain,empty socket and halitosis were present in $8(7.76 \%)$ no. of cases and only pain with empty socket was present in $15(14.56 \%)$ no of cases. Thus pain and empty socket were present in 103(100\%) cases, bare bone was present in $80(78 \%)$ and halitosis was present in $68(66 \%)$ no. of cases (Fig 1).

The onset of symptoms was found to range from immediately to more than 72 hours after the extraction. Symptoms started immediately after the extraction in $5(4.85 \%)$ cases, following 24 hours in 7 (6.79\%)cases, following 48 hours in $23(22.33 \%)$ cases, following 72 hours in $49(47.57 \%)$ cases and following more than 72 hours in $19(18.44 \%)$ no of patients (figure2).

All affected dry sockets were irrigated with normal saline and zinc oxide Eugenol packing was used on 80 (77.6\%) cases. 37 cases were prescribed medications including Ibuprofen $400 \mathrm{mg} /$ Diclofenac potassium $50 \mathrm{mg}$ for 29 cases and a combination of NSAID with Metronidazole and Chlorohexidine mouthwash in 8 cases.

Data was analysed using the SPSS for windows (version 9.0) statistical software package.

Table 1: Occurrence of dry socket by gender and age group

\begin{tabular}{|c|c|c|}
\hline Individuals & Total no. of extractions (\%) & No of dry sockets \\
\hline \multicolumn{3}{|l|}{ A. Gender } \\
\hline Male & $873(47 \%)$ & $47(45.6 \%)$ \\
\hline Female & $987(53 \%)$ & $56(54.4 \%)$ \\
\hline Total $\left(\chi^{2}=11.43, p=0.001\right)$ & $1860(100 \%)$ & $103(100 \%)$ \\
\hline \multicolumn{3}{|l|}{ B. Age ( yr) } \\
\hline$<20$ & 206 & 11 \\
\hline $21-30$ & 1126 & 42 \\
\hline $31-40$ & 386 & 13 \\
\hline $41-50$ & 367 & 10 \\
\hline $51-60$ & 354 & 14 \\
\hline 61 and above & 201 & 13 \\
\hline Total $\left(\chi^{2}=3.43, p=0.019\right)$ & 2640 & 103 \\
\hline
\end{tabular}


Table 2: Distribution of the indications for extraction with the result of dry socket

\begin{tabular}{|l|c|}
\hline Indications for extraction & No (\%) \\
\hline Advanced periodontal disease & $42(40.7 \%)$ \\
\hline Advanced dental caries & $46(44.6 \%)$ \\
\hline Orthodontic treatment & $2(1.9 \%)$ \\
\hline Pericoronitis & $11(10.6 \%)$ \\
\hline Prosthetic reasons & $2(1.9 \%)$ \\
\hline Total & $\mathbf{1 0 3 ( 1 0 0 \% )}$ \\
\hline
\end{tabular}

Table 3: Distribution of extractions and dry socket by tooth type

\begin{tabular}{|c|c|c|}
\hline Tooth type & Total no of extractions (\%) & No. of dry sockets (\%) \\
\hline \multicolumn{3}{|l|}{ Maxillary } \\
\hline Incisors and canines & $556(21.06 \%)$ & $7(6.79 \%)$ \\
\hline Premolars & $407(15.41 \%)$ & $6(5.82 \%)$ \\
\hline First molars & $208(7.87 \%)$ & $11(10.67 \%)$ \\
\hline Second molars & $262(9.92 \%)$ & $3(2.91 \%)$ \\
\hline Third molars & $157(5.94 \%)$ & $5(4.85 \%)$ \\
\hline Total $\left(\chi^{2}=6.75, p=0.2\right)$ & $1590(60.22 \%)$ & $32(31.06 \%)$ \\
\hline \multicolumn{3}{|l|}{ Mandibular } \\
\hline Incisors and canines & $326(12.34 \%)$ & $6(5.82 \%)$ \\
\hline Premolars & $209(7.91 \%)$ & $13(12.61 \%)$ \\
\hline First molars & $266(10.07 \%)$ & $28(27.81 \%)$ \\
\hline Second molars & $142(5.37 \%)$ & $13(12.62 \%)$ \\
\hline Third molars & $107(4.05 \%)$ & $11(10.67 \%)$ \\
\hline Total $\left(\left(\chi^{2}=44.54, p=0.0001\right)\right.$ & $1050(39.77 \%)$ & $71(68.93 \%)$ \\
\hline
\end{tabular}

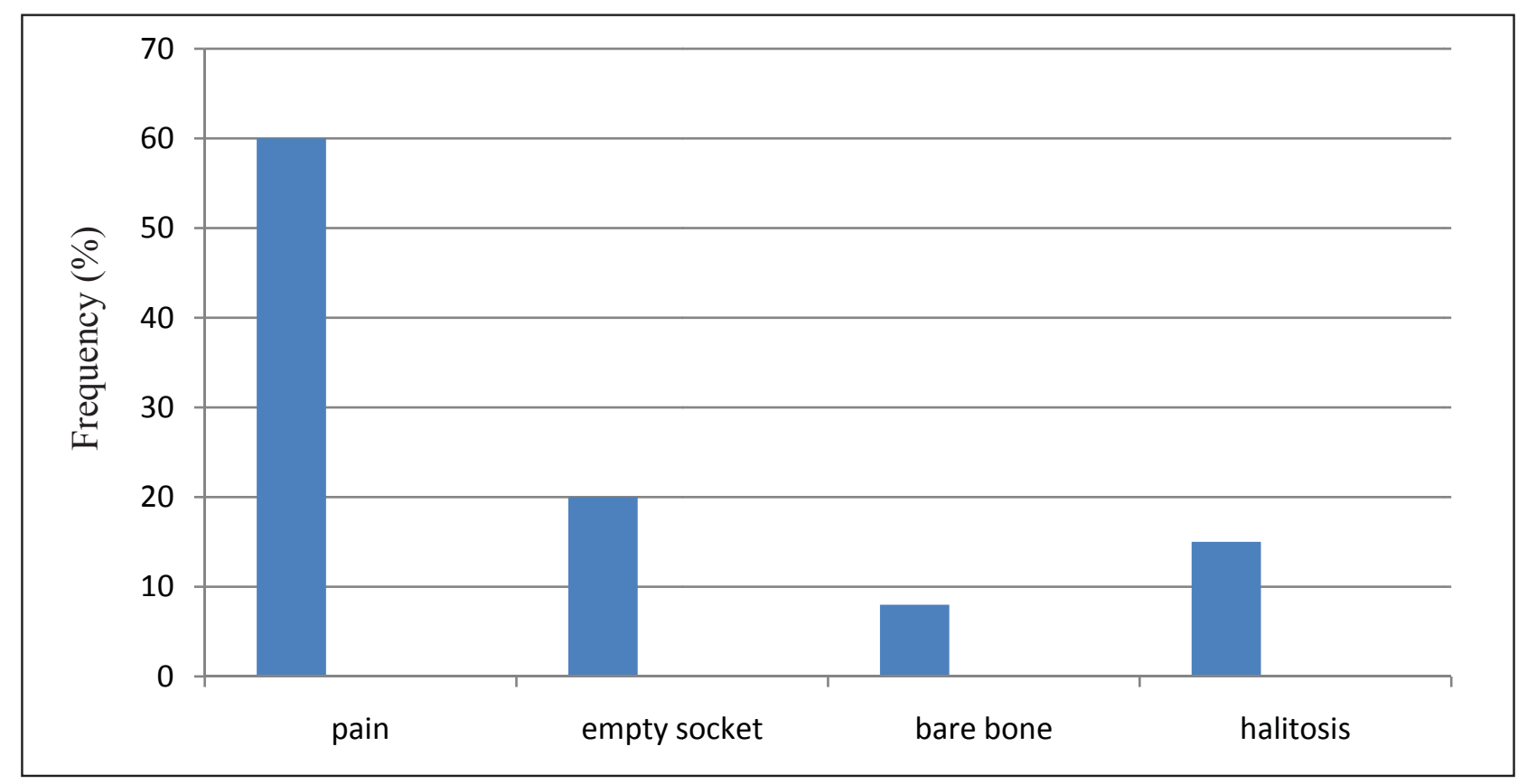

Fig 1: Distribution of clinical features of dry socket 


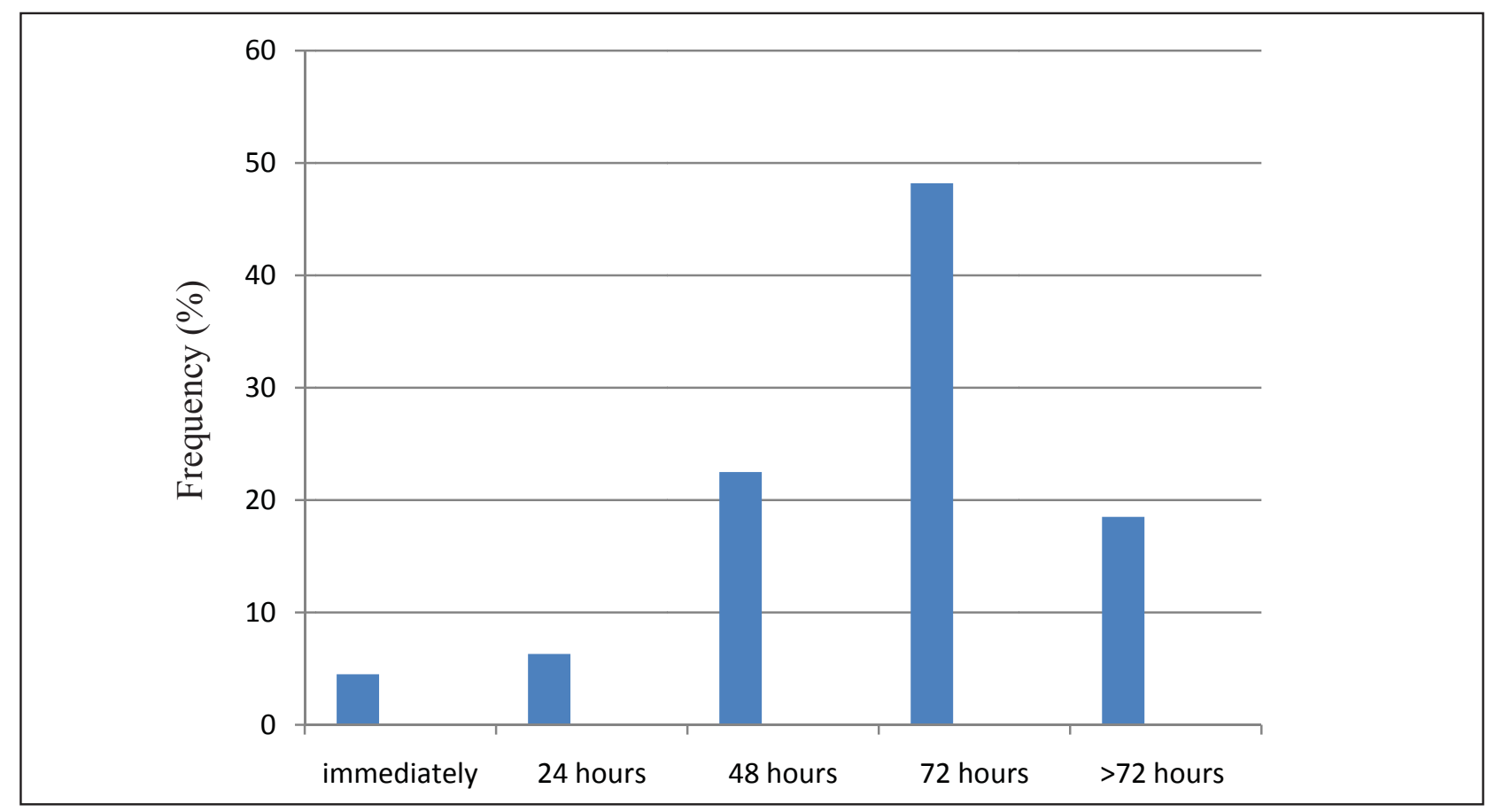

Fig 2: Frequency of dry socket according to onset of time

\section{Discussion}

Dry socket is a clinical complication of considerable importance. It is characterized by severe pain starting usually on the second or third day postoperatively. The generally accepted aetiology of dry socket is an increased local fibrinolysis leading to disintegration of the $\operatorname{clot}^{10}$. Some antifibrinolytic agents when placed topically in the extraction site have been shown to decrease the incidence of dry socket ${ }^{11}$. Surgical trauma, which leads to liberation of different tissue activators, and bacterial infections remain the two most acceptable initiating factors of this localized fibrinolytic activity.

The incidence of dry socket in everyday oral and maxillofacial surgery or dental practice is unavoidable. Most of the studies have given the incidence of dry socket in all extractions as ranging from $2 \%$ to $4.4 \%{ }^{10}$ and as high as $12.5 \%{ }^{11}$ whereas third molar extraction has been associated with an incidence of $0.5 \%{ }^{12}$ to $15 \%{ }^{13}$. This great variability in the reported incidence of dry socket is largely due to differences in diagnostic criteria and in the methods of assessment; in intermingled and conflicting data from non-impacted, partially impacted and fully erupted mandibular third molars extractions, in intraoperative and postoperative management of extraction Sites; in patient populations with respect to age or to surgical techniques or surgical skill. In this study a minimum of pain and an empty socket with or without food debris were considered diagnostic. This study has found an incidence of $3.9 \%$ for all type of permanent teeth extractions performed at this hospital. This figure is slightly higher than figures reported in srilanka ${ }^{14}$ and in some developed countries ${ }^{4,9}$. This variability may be due to differences in diagnostic criteria, intraoperative and postoperative treatment ${ }^{15,16}$, patient's age ${ }^{17}$, medical status, surgical technique and skill ${ }^{17}$, use of oral contraceptives, tobacco and alcohol consumption ${ }^{8}$, feminine gender ${ }^{18}$, intraligamentary injection ${ }^{19}$ etc. Another possible explanation for this slightly higher than expected figure is it reflects the overall prevalence following all extractions, including surgical ones. It is well documented surgical extractions result in a higher dry socket prevalence ${ }^{3}$. Similar to previous studies ${ }^{4}$, a female preponderance was found in this study. However a statistically significant relationship was not established between genders in all patients who had extractions and those with dry socket $(p=0.001)$. Some researchers have attributed this gender predilection to a better health-seeking behaviour of females ${ }^{20}$, whereas others have associated it with the use of oral contraceptive pills, which increase fibrinolytic activity in blood and saliva of women during the menstrual phase ${ }^{21}$.

The study group ranged from 11 to $>63$ years of age and it was similar to the study by MacGregor ${ }^{4}$. These are contrary to claims that dry socket seldom occurs before the $18^{\text {th }}$ or after the $50^{\text {th }}$ year of $1 \mathrm{ife}^{21}$. Also at variance with other reports ${ }^{4}$ but in concordance with that of Amaratunga and senaratne ${ }^{14}$, we have found a peak age incidence of 21 to 30 years. 
Similar to other studies, extraction of mandibular molars constituted more than $50 \%$ of those complicated by dry socket ${ }^{4,14}$ (table-3). Additionally, a significant association was found between teeth with dry socket and patient's age group. Some authors believe increased bone density, decreased vascularity, and a reduced capacity of producing granulation tissue is responsible for this site specificity ${ }^{6}$. This lends some credence to the implications of hypovascularity as a risk factor in the development of dry socket ${ }^{6}$. Most of the previous studies have reported dry socked incidence is most commonly seen in the third molar, second molar and first molars respectively ${ }^{22}$. But in this study we found the incidence most common in first molar, second molar and third molar of mandibular teeth respectively. This pattern is similar to the study done by Amaratunga NA, Senaratne ${ }^{14}$

In this study there was no significant difference in dry socket prevalence following the extraction of teeth requiring infiltration anaesthesia (for upper and lower anterior teeth) and those requiring regional block anaesthesia (both contained adrenaline). These results are in agreement with the assumption of local ischemia due to vasoconstrictors in local anaesthesia have no role in the pathogenesis of dry socket.

The clinical picture of dry socket in this study was comparable to generally described dry sockets in the literature. Pain and empty sockets were found in all patients, which is in agreement with the findings of several authors ${ }^{3,15,23,22}$. The average onset time of symptoms was around 36 hours after the extraction. This relatively early onset could be attributed to the co-existence of dry socket with other postoperative complications such as swelling and trismus. This is understandable when one considers the neurological pain of dry socket is believed to be related to the release of kinins, which are immediately available following tissue trauma. Cases in which the onset was a little more delayed can be explained by the notion that an infection process was needed to liberate tissue activators and pain mediators $^{23}$.

Some researchers had found a relationship between some systemic diseases and dry socket ${ }^{15,3}$. This was in agreement with MacGreoger ${ }^{10}$ and Oginni et $\mathrm{al}^{24}$ With regards to medications, only oral contraceptives have been reported to be associated with an increased risk of dry socket ${ }^{3,25,26,27 .}$

It has been thought, but not conclusively proven that there is a possibility of an increased incidence of dry socket following the use of local anaesthesia with vasoconstrictors before the extraction ${ }^{15}$. Although $\mathrm{Krogh}^{9}$ emphasized the incidence of dry socket was highest in the mandibular molar area (where regional block anaesthesia is used), Lehner43 found a higher incidence of dry socket when infiltration anaesthesia was used and concluded infiltration anaesthesia gave rise to a temporary ischemia leading to poor blood supply to the socket. However, subsequent studies indicate ischemia lasts only for one to two hours and is followed by a reactive hyperaemia which makes it of no importance to the subsequent disintegration of the blood clot $^{15,19}$. This concept is currently widely accepted. In this study there was no significant difference in dry socket prevalence following the extraction of teeth requiring infiltration anaesthesia and those requiring regional block anaesthesia (both contained adrenaline)

Pain was the chief complaint in all patients suffered with dry socket. $81.56 \%$ of the patients whose record showed time of onset of their complaints had it by day 3 (within 72 hours). Late presentation in the majority of our patients may be attributed to easy access to pain relieving tablets, pain tolerance, self-medication, seeking care from elsewhere, poor health-seeking behaviour, or a combination of these and others factors.

The prevention of dry socket is desirable and a number of studies have shown the efficacy of different preventive measures; these include the use of $0.12 \%$ Chlorhexidine gluconate $^{28-29}$ clindamycin $^{30}$, local application of tetracycline ${ }^{11}$, and local application of Lincomycin gel foam $^{11}$. Others are application of Tranexamic acid to alveolar sockets ${ }^{29}$ and use of topical penicillin ${ }^{30}$.

Apart from the use of conventional Eugenolimpregnated iodoform gauze in the treatment of dry socket $^{20}$, the management of dry socket has witnessed many reviews over the years. Some of these are adjunct topical viscous $2 \%$ Lidocaine jelly during management of alveolar osteitis ${ }^{31}$, the use of clindamycin ${ }^{30}$, and the use of buccoadhessive Metronidazole tablets ${ }^{31}$ or topical metronidazole ${ }^{32}$.

As indicated by Fazakerley ${ }^{33}$, the primary aim of dry socket management is pain control until commencement of normal healing, and in the majority of cases local measures are satisfactory. The treatment of dry socket in our centre remains thorough irrigation with warm normal saline and a zinc oxide Eugenol dressing placed snugly in the extraction socket. This is changed on alternate days until the socket granulates adequately. The affordability and availability of zinc oxide Eugenol as well as satisfactory results obtained appear to have encouraged its continual use. Furthermore, although foreign body reaction among other possible adverse reactions to zinc oxide Eugenol has been reported in the literature ${ }^{34}$ we have not found this as a clinical problem. 


\section{Conclusion}

The occurrence of dry socket in an everyday oral surgery or dental practice is unavoidable. The risk factors for this temporary and debilitating condition are clearly identified. However, adherence to superb surgical technique in a young, healthy, and nonsmoking male patient still carries a $1 \%-4 \%$ incidence of dry socket. Surgeons must recognize additional risk factors in patients with particular medical conditions and include this information as a part of the informed consent. Treatment options for this condition are generally limited and directed toward palliative care. The surgical site should be irrigated, avoiding curetting the extraction socket. Packing with a zinc oxide- eugenol paste on iodoform gauze can be considered to relieve acute pain episodes. Ultimately it is the host's healing potential which determines the severity and duration of the condition.

\section{References}

1. Crawford JY. Dry socket. Dent Cosmos. 1896: 38: 929.

2. Erickson RT, Wait DE, Wilkison RH. A study of dry sockets. Oral Surg. 1960;13:1046-50.

3. Lilly GE, Osborn DB, Rael EM, Samuels HS, Jones JC. Alveolar osteitis associated with mandibular third molar extractions. J Am Dent Assoc. 1974; 88:802-6.

4. MacGregor AJ: Aetiology of dry socket: A clinical investigation. $\mathrm{Br} \mathrm{J}$ Oral Surg. 1968;6:49.

5. Lambert S, Reychler H: Dry socket. Prevention and treatment. Rev Stomatol Chir Maxillofac. 1994; 95:435.

6. Kruger G: Textbook of Oral Surgery. $3^{\text {rd }}$ edition. St Louis, MO: CV Mosby; 1968.p. 128.

7. Seldin HM: Accidents in exodontias and how to avoid them. Dental Items. 1933;55:705.

8. Bonine FL: Effect of chlorhexidine rinse on the incidence of dry socket in impacted mandibular third molar extraction sites. Oral Surg Oral Med Oral Pathol Oral Radiol Endod. 1995;79:154.

9. Krogh HW: Incidence of dry socket. J Am Dent Assoc. 1937;24:1829.

10. MacGregor AJ. Aetiology of dry socket: A clinical investigation. $\mathrm{Br} \mathrm{J}$ Oral Surg. $1968 ; 6: 49$.

11. Goldman DR, Kilgore DS, Panzer ID, et al. Prevention of dry socket by local application of lincomycin in Gelfoam. Oral Surg. 1973;35:472.

12. Belinfante LS, Marlow GD, Myers W, et al. Incidence of dry socket complications in third molar removal. J Oral Surg. 1973; 31: 106.
13. Khandker $\mathrm{MH}$, Molla MR. Incidence of dry socket in surgical removal of impacted third molar. Bangladesh Med Res Council Bull. 1994;20:60.

14. Amaratunga NA, Senaratne CM. A clinical study of dry socket in Sri Lanka. Br J Oral Maxillofac Surg. 1988;26:410.

15. Birn H. Etiology and pathogenesis of fibrinolytic alveolitis. Int J Oral Surg. 1973;2:215-63.

16. Ritzau M, Therkildsen P. Antitibrinolytic prevention of alveolitis sicca dolorosa. Int $\mathrm{J}$ Oral Surg. 1978;7:534-40.

17. Alkhateeb TL, El-Masafi AI, Butler NP. The relationship between the indications for surgical removal of impacted third molar and the incidence of alveolar osteitis. J Oral Maxillofac Surg. 1991;49:141.

18. Larsen PE. Alveolar osteitis after surgical removal of impacted mandibular third molar. Identification of the patient at risk. Oral Surg Oral Med Oral Pathol. 1992;73:393.

19. Tsirlis AT, Iakovidis DP, Parissis NA. Dry socket: Frequency of occurrence after intraligamentary anaesthesia. Quintessence Int. 1992;23:575.

20. Preshaw PM, Fisher SE. Routine review of patients after extraction of third molar: Is it justified? $\mathrm{Br} \mathrm{J}$ Oral Maxillofac Surg. 1997;35:393.

21. Hermesch CB, Hilton TJ, Blesbrock AR, et al. Perioperative use of $0.12 \%$ chlorhexidine gluconate for the prevention of alveolar osteitis: Efficacy and risk factor analysis. Oral Surg Oral Med Oral Pathol Oral Radiol Endod. 1998; 85:381.

22. MacGregor AJ, Addy A. Value of penicillin in the prevention of pain, swelling and trismus following the removal of ectopic third molars. Int J Oral Surg. 1980; 9:166.

23. Field EA, Speechley JA, Rotter E, Scott J. Dry socket incidence compared after a 12-year interval. Br J Oral Maxillofac Surg. 1985;23: 419-27.

24. Oginni FO, Fatusi OA, Alagbe AO. A clinical evaluation of dry socket in a Nigerian teaching hospital. J Oral Maxillofac Surg. 2003;61(8):871-6.

25. Catellani JE, Harvey S, Erickson SH, Cherkink D. Effect of oral contraceptive cycle on dry socket (localized alveolar osteitis). J Am Dent Assoc. 1980;101:777-80.

26. Sweet JB, Butler DP. Predisposing and operative factors: Effect on the incidence of localized osteitis in mandibular third molar surgery. Oral Surg Oral Med Oral Pathol. 1978;46:206-15. 
27. Garcia AG, Grana OM, Sampedro FG, Diago MP, Rey JM. Does oral contraceptive use affect the incidence of complications after extraction of a mandibular third molar? $\mathrm{Br}$ Dent $\mathrm{J}$. 2003;194:453-5.

28. Ragno JR Jr, Szkutnik AJ. Evaluation of 0.12\% chlorhexidine rinse on prevention of alveolar osteitis. Oral Surg Oral Med Oral Pathol. 1991;72:524.

29. Gersel-Pedersen N.Tranexamic acid in alveolar sockets in the prevention of alveolitis sicca dolorosa. Int J Oral Surg a.1979; 8:421.

30. MacGregor AJ, Addy A.Value of penicillin in the prevention of pain, swelling and trismus following the removal of ectopic third molars. Int J Oral Surg. 1980; 9:166.
31. Betts NJ, Makowski G, Shen YH, et al. Evaluation of topical viscous 2\% lidocaine jelly as an adjunct during pain management of alveolar osteitis. J Oral Maxillofac Surg. 1995;53:1140.

32. Ahuja A, Hhar RK, Chaudhry R. Evaluation of metronidazole tablets: Microbiological response. Pharmazie. 1998; 53: 264.

33. Fazakerley M, Field EN. Dry socket: a painful post-extraction complication (A review). Dental update. 1991;18:31-34.

34. Mainous EG: Foreign body reaction after zinc oxide eugenol packing in localized osteitis. J Oral Surg. 1974; 32:207. 